\title{
A Brief Analysis of the Characteristics of Moral Identity and It's Mechanisms in the Context of Chinese Traditional Moral Culture
}

\author{
Chunhua Shi ${ }^{1, a}$, Baojun Wang ${ }^{2, b, *}$ and Lin Zhang ${ }^{1, c}$ \\ ${ }^{1}$ School of Administration, Hohai University, Nanjing, China \\ ${ }^{2}$ Institute of Earth Science and Engineering, Nanjing University, Nanjing, China \\ ${ }^{\mathrm{a}}$ chunhuashi828@sina.com, bbaojun@nju.edu.cn, ${ }^{c} 1938811522 @ q q . c o m$ \\ *Corresponding author. Email: baojun@nju.edu.cn
}

\begin{abstract}
Moral identity is a hot issue in psychology and other social sciences. Up to now, the abstract characteristics of moral identity has been studied in psychology, rarely involving it's formation process and content in specific culture. Chinese traditional moral culture, based on Confucianism, emphasizes the extreme importance of morality and the individual's responsibility to practise morality. As a result, moral identity becomes a complex personality structure based on the moral belief of becoming a saint or sage. In Chinese history, with the help of God worship and ancestor worship, the cultural mechanism of constructing moral identity has been formed. The individual mechanism of moral identity construction is not only self-cultivation, but also smelting through social institutions and family. In the future, it is necessary to study the specific content, characteristics and construction mechanism of moral identity in the background of the traditional Chinese moral culture, and study the evolution trend of Chinese moral identity combined with the transformation of contemporary moral culture.
\end{abstract}

Keywords: Moral identity, Moral psychology, Chinese traditional moral culture.

\section{INTRODUCTION}

Moral identity is a hot issue in many scientific fields like philosophy, pedagogy, ethics and psychology. Modern psychology, with psychological measurement and experiment as its basic means or methods, can conduct in-depth study on the abstract characteristics of moral identity. The so-called abstract feature of moral identity is to filter out the particularity of moral rules and emphasis on the importance of morality in each specific moral culture or environment as far as possible, and pay attention to which kind of components of moral identity is relatively higher or lower. For example, is moral identity mainly a kind of moral cognition? Or moral emotion? How are moral cognition, moral emotion and so on related to each other? Is moral belief as the core, connecting moral cognition and moral emotion, and mainly reflected through moral will and moral behavior?

In one of my articles, I have analyzed and pointed out the basic viewpoints or conclusions on the research of moral identity in psychology. In my opinion, psychological research have been carried on to cover the abstract characteristics of moral identity from the following four aspects: (a) There is a tense and balanced development process involving two motivation systems of self-value and group value; (b) It is a self-awareness schema composed of many moral traits; (c) As a moral self-schema, its most important feature or one of the most important characteristics is integration, that is, the high degree of uniformity of cognition, emotion, belief and behavior involved in moral identity; (d) From a certain stage of life, it is similar to some stable personality traits, while from the perspective of life-long development, it is a moral schema that transcends situations and personality traits. [1] Obviously, it is not comprehensive to study these abstract characteristics of moral identity. There is no doubt that in order to grasp the moral identity of individuals or groups, we should not only understand its abstract characteristics or laws, but also investigate its specific content characteristics and construction mechanism. That is to say, individuals or groups actually acquire moral identity in a specific moral culture (environment); the interaction between the internal 
physiological and psychological characteristics of individuals and the external environmental characteristics finally forms the psychological phenomenon of moral identity, which is also a process of continuous cycle. It is worth pointing out that, in a certain sense, the external moral culture moulds which moral values the individual or group will identify with, and even to a certain extent, it may determine the development trend of moral identity with age. Therefore, it is very important for us to understand the moral characteristics of individuals and groups in a comprehensive way. Limited to space, in this paper only a brief analysis of the construction mechanism of moral identity in the background of the traditional Chinese moral culture was presented.

\section{THE FEATURES OF CHINESE TRADITIONAL MORAL CULTURE}

Chinese traditional culture includes three main schools, namely Confucianism, Taoism and Buddhism. Among them, Confucianism constitutes the foundation and is the core of Chinese secular and orthodox traditional moral culture. Therefore, the traditional Chinese moral culture discussed in this paper actually refers to the moral culture under the guidance of Confucian moral thought. Moreover, because the moral thought of the pre Qin Confucianists laid a solid foundation for the later Confucian moral thought, in this paper we mainly presented the introduction of the moral thought of the pre Qin Confucian thinkers.

Confucius' moral thought can be summarized as advocating benevolence and propriety, among which benevolence is more important than propriety. The meaning of benevolence is very broad, the basic meaning is to love, almost contains all the principles of life. Etiquette is the material or system, or norms, which is the embodiment of benevolence and can be used to cultivate the spiritual realm of benevolence. Confucius tried to use the moral ideal of benevolence and the moral standard or moral system of rites to change people's moral decline and restore social order [2]. Mencius put forward the theory of good, which turned the moral ideal into the innate potential and learning quality of everyone. Later Neo Confucianists in the Song and Ming Dynasties turned morality into heavenly principle, and opposed moral and natural principles to human desires, emphasizing that everyone can be a saint or a moral model.

To summarize the characteristics of Chinese traditional moral culture, we can see that: (1) It is to emphasize the extreme importance of morality for individual life and social group life, thus relatively neglecting or belittling the value and significance of material and pleasure; (2) It is to consider that the core quality of morality is kindness or kindness, which basically means respecting and caring for others; (3) The moral thought of Confucianism has become the core and foundation of Chinese traditional moral culture. Under the feudal historical conditions of more than 2000 years, this kind of moral culture has been generally recognized by the ruling class and the public, and has become the highest conscious pursuit of people's spiritual life, but it is also inevitably forced and superficial.

\section{THE MORAL IDENTITY IN CHINESE TRADITIONAL CULTURE IS A COMPLEX PERSONALITY STRUCTURE WITH THE PURSUIT OF BECOMING A SAGE AS THE CORE}

In general psychology, people's personality system is generally divided into the subsystems of individuality tendency, characteristics and self-regulation. Firstly, moral identity is similar to the moral values of individual identification. Secondly, it is similar to a series of related moral characteristics. Thirdly, it is similar to moral self-consciousness. Therefore, moral identity is subordinate to the subsystem of personality dynamics, individual characteristics and personality self-regulation. In fact, moral identity constitutes a complex structure in the personality system, and is the core of the part with moral meaning in personality; because of the importance of moral identity to individual mind and behavior, moral identity is also the core part of the whole personality, especially in those cultures which attach great importance to morality, the formation of corresponding moral identity is an adaptive ring.

In Chinese traditional moral culture, because the moral ideal actually contains the moral pursuit of becoming a saint or sage, and this moral ideal is considered to be gifted, so no one can shirk this moral responsibility. The traditional Chinese moral culture is a culture that emphasizes the importance of morality, and morality becomes the dominant factor in people's spiritual life. Therefore, the understanding of moral norms and the experience of moral emotion are relatively not so important. The most important thing is that people must show good moral behavior in the eyes of others before they consciously practice morality and reach a very high moral realm. That is to say, to be a good person in the eyes of others is more important than knowing that you are a good person. This is intrinsically related to the problem of Chinese Face studied by Zhai Xuewei and other scholars. Face is more about moral behavior, and Mianzi is more about success. In the traditional Chinese view, Face and Mianzi should be homogeneous, through the moral noble person (having Face) to earn the success of life (Mianzi). However, in reality, Face is usually more important than Mianzi, which leads to self deception and / or deceiving others [3] That is to say, in the personality structure of traditional Chinese people's moral identity, although the moral belief of becoming a sage is at the core, the relationship between moral cognition, moral 
emotion, moral will and moral behavior may not be close and may not be consistent with each other. Zhai Xuewei pointed out that the Chinese social behavior orientation is collectivism and the west is individualism, which is not appropriate. Through the analysis of the family structure, in addition to the ethical norms, the authority of parents, the distribution of interests and blood relationship also participate in it, and the four check and balance each other to explain the structure of Chinese social behavior [4].

\section{THE CONSTRUCTION MECHANISM OF MORAL IDENTITY UNDER THE TRADITIONAL CHINESE MORAL CULTURE}

The mechanism of establishing moral identity of pre Qin Confucianists includes: Based on the worship of gods, the theoretical basis of the unity of heaven and human beings was built; based on the worship of ancestors, the foundation of human relations, rites and music was built[5]. That is to say, by using the ancient people's reverence for God, we skillfully put man and God together, and treated human's morality as God's will. In this way, we realized the transformation from God worship to moral worship, and laid a solid foundation for the importance of moral identity. Then the ancient worship of ancestors is used to make the ritual and music civilization extended from the sacrificial ceremony as an important system and norm of morality, thus laying the moral identity on the basis of biological blood relationship and natural emotion.

The establishment of moral identity in pre Qin Confucianists was based on the human relations in reality. According to Confucius, benevolent people love each other, and love begins with loving parents or relatives. Then, starting from the relationship between human relatives, it is concluded that, for example, benevolent people loving others is a universal conclusion deduced from our love for relatives, that is, loving others is benevolence; therefore, a kind of moral theory system. is found Thirdly, it explains the connotation of benevolence from different angles and situations, such as respect and tolerance. Finally, it emphasizes the practice of benevolence in behavior. In other words, human relations, moral reasons, moral characters and moral behaviors consist of a pattern of moral identity. The value goal of national identity is not only based on blood relationship, but also based on cultural and political relations, which is the conception and moral ideal of a great harmony society. The Confucian doctrine of self-discipline and peace is applicable to all people. Finally, to form moral identity, individuals need both internal and external cultivation [6].
To sum up, from a cultural point of view, the reason why morality in traditional Chinese culture can be placed at the same height as the gods, the reason why it has become a kind of Tao (Law) above the ordinary laws and decrees, and the reason why the country and the world become the moral ideal are because of human beings being afraid of nature and depending on blood and tribes. From the individual point of view, the construction of moral identity depends not only on the individual's subjective initiative and self-cultivation, but also on the training, supervision and punishment of various social institutions and families.

\section{CONCLUSION}

Future research needs to make a more accurate statement and more comprehensive demonstration on the detailed characteristics and construction mechanism of moral identity under Chinese traditional culture. It is also necessary to explore the evolution trend of Chinese moral identity from both theoretical and empirical aspects.

\section{ACKNOWLEDGMENT}

This research was financially supported by the National Natural Science Foundation of China, which was The Relationship between Turnover of Scientific Research Personnel and Professional Achievement (project approval No.:71874049)

\section{REFERENCES}

[1] C.H. Shi, B.J.Wang, T.Zhang, A brief analysis of the conception of moral identity in psychology, in: Proceedings of 5th Annual International Conference on Social Science and Contemporary Humanity Develpoment, Information on https:// www.atlantis-press.com/proceedings/sschd-19

[2] Confucius, Analects of Confucius: English Chinese comparison, Foreign Language education and Research Press, Beijing, 1998, preface, pp.3-13.

[3] X.W.Zhai, Chinese face view, Laureate Book Company, Taipei, 1995, pp.153-168.

[4] X.W.Zhai, The structure of Chinese social behavior: the end of individualism and collectivism, J. Nanjing Univ., 1(1998)123-130.

[5] J.J.Gu, The theoretical basis of moral identity construction of pre Qin Confucianism, Tangshan Lit, 10(2018) 118-119.

[6] R.G.Liu, Pre Qin Confucian moral identity wisdom and its contemporary value, Eth. Res.,2(2019) 36-41. 